\title{
AS POLÍTICAS DE EDUCAÇÃO AMBIENTAL E SUAS REPERCUSSÕES SOBRE O PLANEJAMENTO DA EDUCAÇÃO BÁSICA NO ENSINO PÚBLIÇO BRASILEIRO
}

João Paulo Gomes de Aragão ${ }^{1}$

Resumo: $O$ objetivo deste trabalho foi "analisar as políticas de Educação Ambiental no Brasil e suas repercussões sobre o planejamento da educação básica no ensino público". Para tanto, a discussão fundamenta-se em referencial teórico sobre Educação Ambiental crítica e considera a atuação do Estado como importante agente social de condução das políticas públicas de educação. Observada a relevância do tema e sua necessidade de aprofundamento teórico e empírico, sugerem-se ao fim do trabalho eixos de análise para propostas de pesquisa em diferentes realidades de recorte municipal ou estadual no Brasil. A tese aqui proposta repousa na ideia de que há uma desarticulação entre as políticas de Educação Ambiental e o planejamento da educação básica no Brasil, especialmente no contexto material do professorado, seja na esfera pública municipal ou estadual.

Palavras-chave: Políticas de Educação Ambiental; Educação Básica; Ensino Público; Professorado.

\footnotetext{
${ }^{1}$ Instituto Federal de Educação, Ciência e Tecnologia da Paraíba, Joao Pessoa, PB.
} 


\section{Introdução}

As políticas de Educação Ambiental são um dado relativamente recente na história da educação no Brasil e a materialização de suas diretrizes, especialmente, na educação básica no ensino público ainda é questionável, posto o conjunto de contradições e dificuldades que contextualizam a implementação destes instrumentos na realidade educacional escolar. Uma das contradições é o enrijecimento do sistema disciplinar no planejamento da educação básica em detrimento das propostas de interdisciplinaridade e transversalidade contidas na Política Nacional de Educação Ambiental. Este quadro implica reflexões sobre a postura do Estado no processo de planejamento, instituição e implementação das leis educacionais num contexto capitalista de sociedade, até as repercussões sobre o planejamento da educação básica, enfocando questões como a interferência das políticas de EA (Educação Ambiental) nas condições de trabalho dos professores no ensino público brasileiro.

A partir disto questiona-se quais repercussões as políticas de Educação Ambiental têm gerado no planejamento da educação básica no ensino público brasileiro? Concebe-se ainda como questões específicas de análise, a natureza histórica das políticas públicas de educação no Brasil, as políticas ambientais que inserem a educação como ferramenta fundamental de transformação social, - papel do Estado no planejamento da educação básica no contexto socioeconômico capitalista e as condições de trabalho dos professores enquanto atores fundamentais da escola e do processo de praticização das políticas e do planejamento educacional.

Mediante o apresentado é objetivo central deste artigo "analisar as políticas de Educação Ambiental no Brasil e suas repercussões sobre o planejamento da educação básica no ensino público". Para tanto, a discussão fundamenta-se em referencial teórico sobre Educação Ambiental crítica empregada em inúmeros trabalhos por Loureiro $(2009 ; 2004)$, considera a atuação do Estado como importante agente social de condução das políticas públicas de educação e, em termos metodológicos, na análise de políticas de Educação Ambiental como a PNEA, enfocando a forma como as políticas de EA estão presentes no planejamento educacional do ensino, investigando questões como a presença ou não de assuntos ligados às condições de trabalho do professorado.

Com isso pretendeu-se realizar uma investigação cujo método expressasse:

a) questionamentos teóricos e metodológicos para o direcionamento da análise das políticas nacionais, estaduais e, possivelmente, municipais de Educação Ambiental, instigando sobre suas repercussões no planejamento da educação básica do ensino público;

b) Subsídios para investigação dos processos históricos espaciais peculiares e comuns ao quadro das propostas de Educação Ambiental no país; 
c) Proposições de estudo das condições de trabalho dos professores do ensino público a partir da revisão das políticas de Educação Ambiental e do engajamento destas no processo de planejamento da educação básica.

A importância desta proposta é ratificada tanto por seu caráter analítico como pela abrangência teórica e prática que inspira do tema: a Educação Ambiental enquanto política pública. A Educação Ambiental vem sendo trabalhada em consórcio aos vários contextos sociais, como na economia, na política institucional, na ciência e no trabalho, por exemplo. Sua aplicação é, portanto, discutida no âmbito teórico para aplicação nos mais variados setores da vida social. Documentos, leis, políticas públicas, projetos, vem sendo elaborados com o objetivo de instituir uma educação com horizontes mais amplos, especialmente, no que tange ao tratamento das questões ambientais. A Educação Ambiental também aparece atrelada, nos documentos institucionais, aos objetivos fundamentais da sociedade, a exemplo disto, a questão do trabalho.

Neste sentido, é fundamental elaborar estudos que visem averiguar o desenvolvimento destas propostas no contexto socioeconômico mais amplo, bem como em sua dimensão prática em escolas, por exemplo, auxiliando mudanças positivas para os agentes envolvidos diretamente no processo de ensino aprendizagem. Esta investigação guia-se, especialmente, na busca pelas condições de acesso, permanência e qualidade do ensino, fundamentais à educação escolar e a uma sociedade humanizada. Por isso, se reforça a importância da escola enquanto célula social ao estudo e aplicação de uma educação preocupada com a formação de indivíduos com uma renovada capacidade de refletir o mundo de forma autônoma e livre de padronizações.

Nesta perspectiva, introduz-se o tema das políticas de Educação Ambiental e suas repercussões no planejamento da educação básica no ensino público brasileiro. Secundariamente, levantam-se outras questões como a melhoria das condições de trabalho dos profissionais de ensino que é uma meta dos movimentos sindicais da categoria e dependente da eficácia dos documentos legais como a Lei de Diretrizes e Bases da Educação e dos diversos instrumentos da política educacional brasileira, como a Política Nacional de Educação Ambiental, ainda que de modo implícito. 


\section{As políticas de Educação Ambiental e o planejamento da educação básica no ensino público brasileiro}

Segundo Lamosa e Loureiro (2011) a escolha do quadro teórico e conceitual marxista ${ }^{2}$ permite alcançar uma análise crítica do processo de inserção da EA na educação básica e as consequentes implicações para o trabalho docente nas escolas públicas, identificando "como a ideologia dominante opera no âmbito da ação teórica e prática da $E A$, ao deslocar discursivamente as condições de trabalho das práticas cotidianas e pessoais, legitimando estratégias de EA organizadas no plano governamental sem uma profunda vinculação com as políticas educacionais em curso e os rumos do desenvolvimento nacional' (LAMOSA; LOUREIRO, 2011, p. 290).

Existe um juízo sobre as políticas públicas de Educação Ambiental que aponta a produção de ações transformadoras que colaborem na prevenção e enfrentamento dos desafios globais, apoiadas numa governança democrática mais intensa, que estimule uma cidadania reflexiva. Aprender a encarar as ameaças numa sociedade capitalista implica na criação de espaços de inter locução para novas formas de participação política e experiência da vida democrática conduzidas a partir do cotidiano e não das bancadas jurisdicionais.

A reflexão crítica sobre este processo implica na análise teórica de duas vertentes de discussão sobre as políticas públicas de Educação Ambiental: uma que aponta o desenvolvimento relativamente satisfatório das políticas de Educação Ambiental, numa perspectiva de cidadania e reflexividade. Linha esta concebida mais nas mentes dos juristas e escritores idealistas do que pelos professores, estudiosos que observam a realidade da superfície da Terra. Por isso, considera-se de modo mais limitado esta vertente haja vista sua inaplicabilidade em moldes materiais. A outra vertente, concebe as políticas de EA como um plano domesticado para introdução de novas formas de alienação social contextualizadas pela tendência neoconservadora do Estado, na qual este se afasta de seu papel de provedor de serviços como a educação (LIBÂNEO, OLIVEIRA; TOSCHI, 2005).

Um dos argumentos daqueles que concebem um desenvolvimento satisfatório das políticas de EA é exposto por Veiga, Amorim e Blanco (2008) sobre a grande expansão que a Educação Ambiental vem alçando no ensino fundamental. Eles explicam que

2 Lefebvre (1979, p. 29), fazendo referência ao método marxista, explica que este "não dispensa a apreensão, em si mesmo, de cada objeto; o método proporciona apenas um guia, um quadro geral, uma orientação para o conhecimento de cada realidade", destacando sua aplicabilidade. Em seguida, o mesmo autor explica que "em cada realidade, precisamos apreender as suas contradições peculiares, o seu movimento peculiar, a sua qualidade e as suas transformações bruscas; a forma do método deve, pois, subordinar-se ao conteúdo, ao objeto, à matéria estudada" (LEFEBVRE, 1979, p. 29). 
Se fosse uma tarefa encontrar um fenômeno semelhante na história recente da educação formal brasileira, esta expansão somente poderia ser comparada aos significativos avanços obtidos na expansão do acesso ao ensino fundamental na segunda metade dos anos 90. Mais ainda, analisando a evolução da presença da EA, parece que esta reproduz a mesma evolução do ensino fundamental em termos da sua praticamente total - universalização (Ibid., p. 10).

Barbosa (2008) aponta de forma positiva os resultados das políticas de Educação Ambiental e comenta o exemplo da Política Nacional de Educação Ambiental.

A Política Nacional de Educação Ambiental (PNEA) - instituída pela Lei no 9.795/99 - e seu decreto de regulamentação em 2002 têm contribuído para acelerar o processo de institucionalização da Educação Ambiental no país, cujo marco inicial, pelo menos para o ensino formal, foi a Lei no 6.938/81, a qual, ao instituir a Política Nacional de Meio Ambiente, determinou a inclusão da EA em todos os níveis de ensino. Desde 2002, com a regulamentação da PNEA, o Programa Nacional de Educação Ambiental (ProNEA) propõe fortalecer o Sistema Nacional de Meio Ambiente, por meio do qual a PNEA deve ser implementada em regime de colaboração com os entes da Federação. Sua missão é a de contribuir com a educação para a sustentabilidade, para uma sociedade educada ambientalmente (Ibid., p. 7-8).

Este panorama é dado para Barbosa (2008) como importante posto o desafio de se aplicar uma política dentro de uma sociedade de risco indica por Giddens (1991) como um período em que as consequências da modernidade estão se tornando mais radicalizadas e universalizadas do que antes. $O$ ProNEA $^{3}$ e a PNEA seriam mecanismos possibilitadores para a superação destes riscos suscitados por Giddens (1991). É preciso, porém, compreender sua administração. O MEC, por intermédio da Coordenação-Geral de Educação Ambiental (CGEA), e o Ministério do Meio Ambiente, através do Departamento

${ }^{3}$ Barbosa (2008) amplia a visão sobre o ProNEA, explicando que "em abril de 2004, reunidos em Goiânia, técnicos e gestores representantes de secretarias de educação e de meio ambiente reconheceram o ProNEA como orientador de políticas públicas de EA. Esse reconhecimento implica numa compreensão segundo a qual as orientações do ProNEA integram processos nacionais de EA e (re)afirmam a necessidade de uma gestão democrática e compartilhada. $O$ documento produzido sugere que as Comissões Interinstitucionais de Educação Ambiental (CIEAs), vistas como colegiados estaduais representativos e democráticos, juntamente com as redes sociais em EA, sejam fortalecidas e empoderadas, pois estimulam a participação e o exercício do controle social (BARBOSA, 2008, p. 9)

Revbea, São Paulo, V.11, № 2: 263-278, 2016.

revista brasileira 
de Educação Ambiental (DEA), coordenam a PNEA e o ProNEA. Entretanto, em razão da transversalidade da EA, outras instituições públicas federais como ministérios, autarquias, órgãos estatais, vêm desenvolvendo ações de EA, fato que desafia o órgão gestor a possibilitar ações integradas para a partir de uma visão sistêmica, fortalecer a implementação da política pública (LAMOSA; LOUREIRO, 2011).

Segundo Sorrentino (et al, 2005, p.289) "a política pública pode ser entendida como um conjunto de procedimentos formais e informais que expressam as relações de poder e se destina à resolução pacífica de conflitos, assim como a construção e ao aprimoramento do bem comum". As políticas públicas de Educação Ambiental têm servido ao desenvolvimento de inúmeros projetos, amplamente divulgados e analisados nos meios de comunicação diversos e nas revistas científicas, a exemplo dos trabalhos já citados de, Veiga, Amorim e Blanco (2005), Sorrentino (2005) e Lamosa e Loureiro (2011). Estes últimos destacam que as próprias políticas públicas não fogem do contexto conflituoso da sociedade e citam o exemplo da PNEA, no que tange aos conflitos internos ao Estado.

As políticas públicas são entendidas [...] como produto das disputas internas no Estado brasileiro. Tais disputas ocorrem entre grupos organizados na sociedade civil que procuram ocupar os espaços estratégicos na burocracia estatal, buscando a hegemonia no Estado ampliado. No caso da PNEA, não é diferente: o Ministério da Educação e o Ministério do Meio Ambiente, que formam o Órgão Gestor (OG), instância executiva da PNEA (1999-2010), são disputados por grupos com interesses e projetos divergentes. A ocupação do OG dá-se por meio dos postos na CGEA/MEC, no Departamento de Educação Ambiental do Ministério do Meio Ambiente (DEA/MMA), na Câmara Técnica, vinculada ao Conselho Nacional do Meio Ambiente, e no Comitê Assessor, formado por diversas instâncias da sociedade civil (Ibid., p. 34).

Observando por este prisma, autores como Carvalho (2006), Aragão, Santos e Silva (2012), apoiados em Morin (2004), Freire (2011) e Boff (1997), demonstram que as políticas públicas de EA não vêm suprindo às demandas da sociedade, especialmente em relação ao contexto de trabalho nas escolas, o que implica na existência de contradições, inclusive, em relação ao Estado ${ }^{4}$ na implementação e avaliação destas políticas em sua dimensão mais concreta. Estas políticas integram um grupo de ações que não atingem os problemas históricos da educação escolar brasileira e seus mecanismos de exclusão

${ }^{4} \mathrm{O}$ conceito de Estado ampliado utilizado neste artigo foi desenvolvido por Antônio Gramsci. O Estado é, portanto, compreendido como uma relação social e histórica em que sociedade civil e sociedade política existem em relação permanente (BUCI-GLUCKSMANN, 1980).

Revbea, São Paulo, V.11, № 2: 263-278, 2016. 
(GENTILI, 2008), o que indica que as mesmas são pensadas de um ponto tão alto do céu que, ao se aproximarem da superfície terrena, onde estão nossas escolas, sua luz já fosse tão fraca, que por consequência, as interpretações de professores, gestores e funcionários são tão limitadas que a ideia de uma Educação Ambiental e Interdisciplinar é dissolvida.

Este tipo de política é insistentemente repetida na história da educação brasileira. Como fruto disto, assiste-se no país um forte setorialismo educacional que extratifica até os professores, entre aqueles universitários, mais ligados à esfera federal e próximos às possibilidades de pesquisa e extensão em atividades de meio ambiente; e aqueles professores dos municípios, cuja organização do trabalho Ihes retira todo o tempo para o trabalho com as tarefas básicas da escola, inviabilizando a pesquisa e o estudo. Não se trata apenas de uma questão de mérito de conquista a um emprego federal ou municipal, mas de falta de reconhecimento das condições ideais de trabalho do professor que, por conseguinte, torna-se órfão três vezes: uma, da estrutura com osteoporose do sistema educacional, duas do tempo que lhe seria fundamental para pesquisa e extensão não reconhecidos, e três pela ausência de participação na operacionalidade das políticas públicas, oferecidas como dádivas divinas, especialmente, (mas não de forma generalizada) em escolas municipais e estaduais.

Teóricos como Meszáros (2008) explicam que as limitações do Estado em ações como as políticas públicas instituídas por este se devem ao contexto socioeconômico da sociedade determinado pela lógica do capital no sistema produtivo. Meszáros (2008) explica que

Limitar, portanto, uma mudança educacional radical às margens corretivas interesseiras do capital significa abandonar de um só vez, conscientemente ou não, o objetivo de uma transformação qualitativa [...] É por isso que é necessário romper com a lógica do capital se quisermos contemplar a criação de uma alternativa educacional significativamente diferente (Ibid., p. 27).

O ponto crítico das políticas de Educação Ambiental, que se estendem do próprio Estado através da manutenção sobre o ensino público de condições desfavoráveis de operacionalidade das políticas de Educação Ambiental, sem materializar as mudanças socioestruturais às quais estas políticas deveriam suceder, compromete a qualidade da educação exigida pela sociedade (WEBER, 1996). Esta realidade coloca o Estado em contradição. Bourdieu (1998) fundamenta a contradição crônica entre a mão esquerda do Estado que reúne os trabalhadores sociais, educadores e professores, inspirando-os na tomada de ações, e a mão direita do Estado que gera a ilusão ante os paradoxos que atingem aqueles, como a falta de recursos, o aumento da desigualdade social, entre outros. Como a mão esquerda atua em degraus de 
administração pública mais elevada, tem-se que a mão direita é aquela que mais repercute e, com isso, corrobora para o insucesso de políticas como as de EA que tendem a serem esfareladas na realidade crua.

Morin (2004) tenciona que só repensando o modelo de sociedade, bem como as políticas umbilicalmente geradas neste modelo que será possível reformar as formas de pensar e fazer a educação. Estas formas de pensar precisam, parafraseando Marx, ser colocadas de cabeça para baixo, considerando as formas atuais. As bases para esta mudança encontram-se, porém, submetidas ante a alienação imposta pelo contexto social e econômico à medida que se identifica no discurso dos atores hegemônicos (grandes empresas e firmas transnacionais, além das elites políticas dos países do primeiro mundo) as justificativas que alimentam o atual modelo de produção e consumo (ARANHA, 2006), reproduzido com o auxílio do Estado. Este padrão de governança, além de arbitrário, apoia-se na educação como ferramenta de formação de capital humano a serviço do sistema de produção, isto é, do mercado de trabalho, realizando um desenvolvimento que antes da emancipação do homem, da instrumentalização enquanto cidadão, gera em mão única e perversa, sua má inclusão na sociedade de consumo pré-fabricada.

Para tanto, este sistema socioeconômico apropria-se da lógica como são definidas e aplicadas as principais políticas, e dentre estas estão as políticas públicas que regem a qualidade da educação na sociedade, principalmente, nas escolas, um dos espaços mais importantes para a reprodutibilidade deste regime. A escola pública, ainda distante da qualidade almejada, surge como cenário de acontecimentos contraditórios. A contradição reside no fato da própria escola, sobretudo a pública, alimentar o insucesso de políticas como as de Educação Ambiental através da limitação imposta sobre as propostas que se tornam corriqueiras com atividades disciplinares desarticuladas da vida experiencial e pontuais, pautadas, segundo Freire (1981), numa consciência ingênua ${ }^{5}$. Caso exemplar para a distorção promovida pela aplicação da PNEA (Política Nacional de Educação Ambiental) nas escolas estaduais de Pernambuco entre educadores, gestores, técnicos e alunos foi a criação da disciplina de "Educação Ambiental". Esta trama contradiz o exposto pelo decreto № 4.281 de 25 de junho de 2002 que regulamentou a Lei no 9.795 de 27 de abril de 1999, que instituía a própria Política Nacional de Educação Ambiental.

Ferramenta fundamental para o desenvolvimento de uma gestão educacional atrelada aos valores ambientais, a PNEA traz as diretrizes ao desenvolvimento da Educação Ambiental. Uma destas diretrizes está no Art. 5oㅜ da PNEA que traz o texto

${ }^{5}$ Para Freire (1981, p. 40) a consciência ingênua "revela uma certa simplicidade, tendendo a um simplismo, na interpretação dos problemas, isto é, encara um desafio de maneira simplista ou com simplicidade. Não se aprofunda na causalidade do próprio fato. Suas conclusões são apressadas, superficiais".

Revbea, São Paulo, V.11, № 2: 263-278, 2016. 
$\mathrm{Na}$ inclusão da Educação Ambiental em todos os níveis $\underline{\mathrm{e}}$ modalidades de ensino ${ }^{6}$, recomenda-se como referência os Parâmetros e as Diretrizes Curriculares Nacionais, observandose: I - a transversalidade continuidade e a permanência ${ }^{7}$, II - A adequação dos programas vigentes de formação continuada de professores (GOVERNO FEDERAL. 2011, s/n).

Como se observa não há indicação para criação de disciplina ou novos elementos curriculares, mas sim a promoção de um saber incluído de forma vertebral, isto é, transversal, além de contínua e permanente em todos os níveis de ensino, considerando como pré-requisito a adaptação continuada de professores, fatos que igualmente não acontecem na atualidade. Mais que uma má interpretação da lei, este fato indica abertamente que as raízes da Política Nacional de Educação Ambiental, estão fora da escola, ou pelo menos que seu cultivo não foi feito por seus semeadores, isto é, professores e professoras.

$\mathrm{Na}$ PNMA (Política Nacional de Meio Ambiente), Lei № 6.938 de 31 de agosto de 1981, tem-se que conforme 0 art. $2^{\circ}$ inciso X, a Educação Ambiental deve ser desenvolvida "a todos os níveis de ensino", de modo transversal. Carvalho (2006) apresenta a Educação Ambiental como ação educativa, bem dizer ramo da educação ${ }^{8}$, responsável pela formação de atitudes e sensibilidades ambientais. A autora indica que, de acordo com a legislação, são aspectos fundamentais a transversalidade, a continuidade e permanência, a interdisciplinaridade, a obrigatoriedade em todos os níveis de ensino e a composição em caráter de urgência e essencial ao ensino fundamental.

Outro aspecto da Educação Ambiental, segundo os documentos anteriormente citados, é que a mesma se dará de forma sistemática e desenvolvida em todos os níveis do ensino formal. A educação básica, composta pela educação infantil, ensino fundamental e médio, abrange as etapas fundamentais para o desenvolvimento dos encaminhamentos das políticas de EA. Libâneo, Oliveira e Toschi (2005) explicam que

A educação básica tem por finalidade desenvolver o educando, assegurando-lhe a formação comum indispensável para o exercício da cidadania e fornecendo-lhe meios para progredir no trabalho e em estudos posteriores. Suas etapas são educação infantil, ensino fundamental e ensino médio (Ibid., p. 252)

\footnotetext{
${ }^{6}$ Grifo do autor

7 Grifo do autor

${ }^{8}$ Sob o nosso ponto de vista, a educação é por essência ambiental. Isto também implica em outro questionamento, pois afinal, pra que setorializar a política de educação? Em que medida a criação de uma política para a EA é uma maneira de evidenciar a importância de um tema ou de torná-lo complementar? Fato é que, ainda que discutida em universidades e grupos de pesquisa diversos, a forma como a Educação Ambiental foi concebida ainda the confere um status de componente pérfido do currículo escolar. Na dimensão do fazer das escolas, acreditase que disciplinas tradicionais do currículo escolar podem dar a real projeção que o TEMA exige atualmente, tais quais a Geografia, a Física, a Matemática, a Língua Portuguesa, dentre outras de igual importância.
}

revista brasileira educação ambiental 
A educação infantil é uma das recentes tarefas colocadas ao Estado a partir da constituição de 1988, aparecendo na LDB de 1996, como incumbência dos municípios. A educação infantil tem como meta o desenvolvimento integral da criança até 6 anos de idade em seus aspectos físico, psicológico, intelectual e social, complementando a ação da família e da comunidade. Nesta idade, o contato com as noções de ambiente e equilíbrio social e ecológico são básicas, todavia necessárias para o trabalho mais organizado no ensino fundamental.

O ensino fundamental, por sua vez, é etapa obrigatória da educação básica e a ele são destinadas as maiores atenções das políticas de EA. Em um dos objetivos do ensino fundamental apresentados pelo art. 32 da LDB para a formação de cidadãos é exposto o desenvolvimento da capacidade de aprendizagem tendo em vista a aquisição de conhecimentos e habilidades e a formação de atitudes e valores (LIBÂNEO; OLIVEIRA; TOSCHI, op. cit.), o que é destacado por inúmeros autores sobre a importância da Educação Ambiental no ensino fundamental.

Como última etapa da educação básica o ensino médio é dado mediante conclusão do ensino fundamental. A consolidação e o aprofundamento dos saberes adquiridos do ensino fundamental é uma das metas estabelecidas pelo art. 32 da LDB, implicando no contexto das questões ambientais um amadurecimento ante as inúmeras dimensões da realidade.

Ao longo deste processo, essencialmente de construção e experiências, os professores são agentes fundamentais uma vez que devem atuar ativamente e de modo sistematicamente planejado na construção da capacidade humana ${ }^{9}$ de refletir as questões ambientais. Todavia, estariam os professores conscientes das diretrizes das políticas de EA e, eles próprios com suas experiências, sendo incorporados no planejamento da educação básica, considerando os vínculos estruturais como 0 trabalho $e$ as práticas sociais numa perspectiva emancipatória (LAMOSA; LOUREIRO, op. cit.), conforme as políticas públicas de Educação Ambiental sugerem? Ou estariam participando de um processo contraditório de sociometabolização (MESZÁROS, 2002) a serviço das necessidades da ordem política neoliberal e dos projetos de sociedade e produção capitalista?

A práxis das normas da Educação Ambiental nas escolas revela contradições em sua aplicabilidade. Mais que indicar uma perda nas exigências das leis federais e estaduais que a instituem, as práticas no espaço escolar

\footnotetext{
${ }^{9}$ Amartya Sen (2000), a partir de sua concepção tanto idealista, porém voltada para as bases da sociedade em detrimento do capital, difere o 'capital humano' tantas vezes enfatizado pelas lideranças mundiais como o Bird (Banco Mundial) nas análises econômicas contemporâneas, da noção de 'capacidade humana'. Ele explica que "correndo o risco de simplificação excessiva, pode-se dizer que a literatura sobre capital humano tende a concentrar-se na atuação dos seres humanos para aumentar as possibilidades de produção. A perspectiva da capacidade humana, por sua vez, concentra-se no potencial - a liberdade substantiva - das pessoas para levar a vida que elas têm razão para valorizar e para melhorar as escolhas reais que elas possuem (SEN, 2000, p. 334).
}

Revbea, São Paulo, V.11, № 2: 263-278, 2016. 
evidenciam um quadro de descomprometimento e incoerência das várias esferas do poder público e de dificuldades das unidades escolares em transformar o ensino atribuindo aos conteúdos escolares a dimensão ambiental, tal como o fazem com a dimensão econômica, cultural e política, por exemplo. Além disso, tencionam a ideia da incorrigível lógica da educação capitalista, analisada por Meszáros (2008), que teria na Educação Ambiental uma nova forma de organização sócio metabólica da educação.

No contraponto desta possibilidade a Educação Ambiental pode ser entendida como um processo com fins à superação das perturbações promovidas pela sociedade capitalista sobre a natureza (CARVALHO, op. cit.). De acordo com a Conferência Internacional sobre Educação Ambiental realizada em Tbilisi (ex - URSS), 1987, pela ONU, a Educação Ambiental também pode ser entendida como processo permanente no qual os indivíduos e a comunidade tomam consciência do seu ambiente e adquirem conhecimentos, habilidades, experiências, valores e a determinação que os tornam capazes de agir, individual ou coletivamente, na busca de soluções para os problemas ambientais, presentes e futuros.

Acredita-se que a Educação Ambiental é em termos práticos um processo político ideológico e social, e não um mero produto, das relações do Homem com o meio natural. É um processo de reconhecimento do ambiente, não como divindade a ser idolatrada, mas como meio que possibilita a vida em contextos que podem ser, muito ou pouco, transformados pelo Homem, sendo passíveis à conservação, à degradação ou a sua recuperação.

As políticas públicas de Educação Ambiental institucionalizadas no Brasil recentemente não podem ser tomadas como um produto acabado e livre do economicismo e das ideologias de grupos hegemônicos e classes sociais dominantes. Elas precisam, sim, ser contextualizadas na esteira da história social, especialmente da história do presente das sociedades globalizadas e viventes num mundo de desigualdades.

Dentre as políticas públicas de EA criadas no Brasil, cita-se: a criação do Programa Nacional de Educação Ambiental (Pronea) em 1984; a inclusão da EA (Educação Ambiental) como direito de todos e dever do Estado no capítulo de meio ambiente da constituição em 1988; a criação dos núcleos de EA pelo Instituto Brasileiro do Meio Ambiente e dos Recursos Naturais Renováveis (IBAMA) e dos Centros de EA pelo Ministério da Educação (MEC) em 1992; a elaboração dos Parâmetros Curriculares definidos pela Secretaria de Ensino Fundamental do MEC, em que "meio ambiente" é incluído como tema transversal em 1997; e, a regulamentação da Política Nacional de Educação Ambiental (Lei 9.795) pelo Decreto 4.281 em 2002.

Logo, a instituição destas e outras políticas públicas de EA pelo Estado não pode aparecer como marcos sem determinações sociais e históricas. É preciso questionar sua natureza, averiguando se as propostas atendem às demandas originais da sociedade presente para uma educação para além do capital ou se o trabalho de seus atores principais (como os professores) segue

revista brasileira educação ambiental 
sendo submetido, do ponto de vista físico, material, por engrenagens a serviço da educação capitalista (MESZÁROS, 2002).

Crê-se, pois, que o trabalho ${ }^{10}$ é uma questão fundamental a ser debatida no tocante às repercussões das políticas educacionais de EA no planejamento da educação básica no ensino público, haja vista sua dimensão teórica e filosófica indicada por Marx em "O Capital" (2008), bem como na dimensão prática, com problemas como as precárias condições de trabalho às quais muitos profissionais de ensino são submetidos diariamente, tais como: insegurança, deficientes condições de saúde no trabalho, má infra estrutura física das escolas, deficiência na acessibilidade ao trabalho, baixos salários, pouco incentivo à pesquisa e qualificação, não reconhecimento de atividades realizadas fora da escola, dentre outros.

Estas questões articulam-se ao plano de incoerências da estruturação em classes da sociedade, legitimado pelo capitalismo em sua fase superior, sem embargos denominada globalização. Estas ações têm contribuído, historicamente, para o desligamento do Homem em relação ao trabalho e sua autocognoscibilidade. Trata-se, segundo Schmidt (1977), da imposição pela ordem capitalista de um projeto de sociedade viabilizado pelo valor de troca sobre a natureza, o que inclui o trabalho expropriado dos homens pelo capital (MARX, op. cit.).

Logo, a questão do trabalho, a partir das políticas públicas de Educação Ambiental, aparece como um aspecto importante, dado o engajamento de inúmeros agentes, especialmente, o professorado num meio (a escola, em específico) no qual não se encontra desligado do sistema de relações sociais de trabalho, visto no capitalismo enquanto sistema sociometabólico de produção (MESZÁROS, 2002). O que introduz o questionamento do "para quê" e/ou "para quem" estariam as políticas públicas de Educação Ambiental a serviço, dentro da definição e operacionalidade proposta pelo Estado.

Destarte, verifica-se a Educação Ambiental como importante elemento de questionamento das políticas e do planejamento educacional com a dimensão ambiental, preenchida de relevância social a partir da segunda metade do século XX. O diálogo entre a crise ecológica e social com novas reflexões e concepções críticas de sociedade demonstra-se não apenas necessário, mas conveniente, inclusive, no cerne do debate de classes sociais como o professorado.

10 Segundo estudiosos como Carvalho (2006), (LAMOSA e LOUREIRO, 2011) e Dias (2006; 1993) há uma desarticulação entre Educação Ambiental e trabalho, tanto no contexto, empírico e filosófico da práxis dos profissionais de ensino, como na instituição das políticas de educação no Brasil. Deste modo, são camufladas as condições de trabalho às quais o professorado do ensino público é por vezes submetido. Promove-se ainda a superficialidade da Educação Ambiental que, longe de suas reais possibilidades de reflexão crítica introduzidas pela Conferência Internacional sobre Educação e Formação Ambiental de 1987 e reforma do pensamento defendidas por autores como Morin (2004), é aplicada como mera ferramenta de estudo desprovida de qualidades políticas, sociais e ideológicas. 
Crê-se que a continuidade desta discussão esteja no viés de construção de um novo pensamento conduzido pelos agentes sociais articulados às escolas, a partir de sua atuação no planejamento educacional e nas transformações necessárias sobre as políticas de Educação Ambiental, além do engajamento da dimensão do trabalho como um elemento fundamental da educação, forçosamente setorializada.

\section{Considerações finais}

As escolas públicas estaduais e municipais integram a delimitação metodológica mais interessante para pesquisas empíricas neste eixo temático. Nelas as ações dadas como Educação Ambiental encontram no Estado, seja na esfera estadual ou municipal, a referência para o delineamento e controle, mesmo que aparente, das ações. Em termos práticos, observa-se que os projetos e demais práticas de Educação Ambiental não têm abrangido as questões relativas ao trabalho como reorganização da carga horária docente e formação inicial e continuada de professores (LIMA, 2007; LOUREIRO; COSSío, 2007), se aproximando de um compêndio de projetos de Educação Ambiental que trabalham a realidade do mundo e local de modo dual, fragmentado, pautando-se numa visão naturalista com forte influência disciplinar na reflexão sobre ambiente ${ }^{11}$ e gerando desdobramentos adversos dado a assimetria com que coexistem o ensino público municipal e estadual em relação a aspectos como verbas disponíveis, infraestrutura e planejamento educacional.

A tese aqui proposta repousa na ideia de que há uma desarticulação entre as políticas de Educação Ambiental e o planejamento da educação básica no Brasil, especialmente na esfera pública municipal e estadual. Essa desarticulação tem gerado diferentes desdobramentos entre a esfera municipal e estadual do ensino público, uma vez que nestes não só a estrutura das escolas como a instituição das políticas educacionais tem seguido rumos e realidades distintas, tanto do ponto de vista do planejamento, como no contexto material do professorado, classe fundamental neste processo.

Isso pode ser comprovado através da análise das contradições e dificuldades que tais políticas apresentam em sua aplicação nas unidades de ensino, com o exemplo do quadro de dificuldades enfrentado por professores em seu cotidiano escolar e nas limitações do Estado frente ao sistema socioeconômico vigente. Dentre os aspectos do quadro exposto estão: a) a inviabilidade prática de uma Educação Ambiental enquanto processo de revitalização ambiental, dentro do molde socioeconômico capitalista acatado pelo Estado; b) a simplificação das ações da Educação Ambiental em projetos pontuais e desarticulados da complexidade do mundo e das questões

11 Em trabalho sobre o engajamento da Educação Ambiental em escolas públicas Bigotto (2008, p. 38), reforça que a "Educação Ambiental está longe de ser uma atividade tranquilamente aceita e desenvolvida, pois ela implica em mudanças profundas, principalmente nos modos de pensar e agir já consolidados pela modernidade".

Revbea, São Paulo, V.11, № 2: 263-278, 2016.

revista brasileira educação ambiental 
socioambientais que envolvem a escola e seus atores; e c) o ocultamento da dimensão do trabalho, pilar de reflexão das relações sociais, nas políticas de Educação Ambiental e no planejamento da educação básica no ensino público brasileiro.

Dada a relevância do tema e sua necessidade de aprofundamento teórico e empírico, sugerem-se eixos de análise para propostas de pesquisa em diferentes realidades de recorte municipal ou estadual no Brasil: a) investigação o contexto histórico e socioeconômico de criação e implementação das políticas de Educação Ambiental; b) avaliação do planejamento da educação básica a partir de instrumentos referenciais como os Parâmetros Curriculares Nacionais e documentos específicos do planejamento escolar como os projetos político pedagógicos (PPP's) em escolas públicas estaduais e municipais; c) discussão sobre a atuação do Estado na elaboração de políticas educacionais e no planejamento da educação básica no em municípios de áreas de forte dinamismo econômico com contexto socioeconômico capitalista; d) estudos de identificação de possibilidades de contribuir na melhoria das políticas de Educação Ambiental e sua inserção no planejamento educacional escolar, especialmente, no que tange às condições materiais de trabalho do professorado no ensino público.

\section{Referências}

ARAGÃO, J.P.G.V.; SANTOS, K.M.B.; SILVA, M.M. Gestão Ambiental e Escola: a construção de uma atitude ambiental. Ambiente \& Educação | vol. 16(2) Porto Alegre: Universidade Federal do Rio Grande do Sul, 2012.

ARANHA, M.L.A. Filosofia da Educação. São Paulo: Editora Moderna, 2006.

BARBOSA, L.C. Políticas públicas de Educação Ambiental numa sociedade de risco: tendências e desafios no Brasil. Brasília: IV Encontro Nacional de Annpas, 2008.

BIGOTTO, A.C. Educação Ambiental e o desenvolvimento de atividades de ensino na escola pública. Dissertação de Mestrado. São Paulo: USP, 2008.

BOFF, L. A águia e a galinha. São Paulo: Vozes, 1997.

BOURDIEU, P. Contrafogos. Rio de Janeiro: Zahar, 1998.

BUCl-GLUCKSMANN, C. Gramsci e o estado. Rio de Janeiro: Paz e Terra, 1980.

CARVALHO, I.C.M. Educação Ambiental: a formação do sujeito ecológico. São Paulo: Editora Cortez, 2006.

DIAS, G.F. Educação e Gestão Ambiental. São Paulo: Gaia, 2006.

DIAS, G.F. Educação Ambiental: princípios e práticas. São Paulo: Gaia, 1993.

FREIRE, P. Educação como prática de liberdade. São Paulo: Paz e Terra, 2011. 
FREIRE, P. Educação e mudança. São Paulo: Paz e Terra, 1981.

GENTILI, P. (Org.). Pedagogia da exclusão: crítica ao neoliberalismo em educação. 15. ed. Petrópolis: Vozes, 2008.

GIDDENS. A. As conseqüências da modernidade. São Paulo: UNESP, 1991.

GOVERNO FEDERAL. Política Nacional de Educação Ambiental. Lei no 9.795 de 27 de abril de 1999, que dispõe sobre a Educação Ambiental, institui a Política Nacional de Educação Ambiental e dá outras providências. In: http://www.planalto.gov.br/ccivil 03/Leis/L9795.htm. Acesso em 15 de maio de 2011.

GOVERnO FEDERAL. Política Nacional de Meio Ambiente. Lei № 6.938 de 31 de agosto de 1981, dispõe sobre a Política Nacional do Meio Ambiente, seus fins e mecanismos de formulação e aplicação, e dá outras providências. In: http://www.planalto.gov.br/ccivil 03/Leis/L6938.htm. Acesso em 15 de maio de 2011.

LAMOSA, R.A.C.; LOUREIRO, C.F.B. A Educação Ambiental e as políticas educacionais: um estudo nas escolas públicas estaduais de Teresópolis (PE). São Paulo: Educação e Pesquisa, v. 37, n.2, p. 279-292, mai./ago. 2011

LEFEBVRE, H. O marxismo. São Paulo - Rio de Janeiro: Difel, 1979.

LIBÂNEO, J.C.; OLIVEIRA, J.F.; TOSCHI, M.S. Educação Escolar: políticas, estrutura e organização. São Paulo: Cortez, 2005.

LIMA, M.J.G.S. O que fazem as escolas que fazem Educação Ambiental no Rio de Janeiro? In: Reunião anual da ANPED: 30 anos de pesquisa e compromisso social, 30., 2007, Caxambu. Anais... Caxambu, 2007. CD-ROM.

LOUREIRO, C.F.B. Mundialização do capital, sustentabilidade democrática e políticas públicas: problematizando os caminhos da Educação Ambiental. Ambiente e Educação, Rio Grande, v. 14, 2009.

LOUREIRO, C.F.B. Educação Ambiental transformadora. In: LAYRARGUES, P. P. (Org.). Identidades da Educação Ambiental brasileira. Brasília: MMA/DEA, 2004. p. 65-84.

LOUREIRO, C.F.B.; COSSíO, M.F.B. Um olhar sobre a Educação Ambiental nas escolas: considerações iniciais sobre os resultados do projeto "O que fazem as escolas que dizem que fazem Educação Ambiental". In: MELLO, S.; TRAJBER, R. (Orgs.) Vamos cuidar do Brasil: conceitos e práticas em Educação Ambiental. Brasília: MEC/UNESCO, 2007. p. 57-64.

MARX, K. O capital. São Paulo: Civilização Brasileira, 2008.

MÉSZÁROS, I. Para além do Capital: rumo a uma teoria da transição. Campinas: Editora da Unicamp, 2002.

MÉSZÁROS, I. A educação para além o capital. São Paulo: Boitempo, 2008.

MORIN, E. A cabeça bem feita: repensar a reforma e reformar o pensamento. Rio de Janeiro: Bertrand Brasil, 2004. 
SCHMIDT, A. El concepto de naturaleza em Marx. Madrid: Biblioteca Del pesamiento socialista, 1977.

SEN, A. Desenvolvimento como liberdade. São Paulo: Companhia das Letras, 2000.

SORRENTINO, M. et al. Educação Ambiental como política pública. Educação e Pesquisa, São Paulo, v. 31, n. 2, p. 285-299, maio/ago. 2005.

VEIGA, A..; AMORIM, E.; BLANCO, M. Um retrato da presença da Educação Ambiental no ensino fundamental brasileiro: o percurso de um processo acelerado de expansão. Brasília: Instituto Nacional de Estudos e Pesquisas Educacionais Anísio Teixeira, 2005.

WEBER, S. Professorado e o papel da educação na sociedade. São Paulo: Papirus, 1996. 